\title{
Criança, infância e cidadania: diálogos de inspiração em Paulo Freire
}

\section{Child, childhood and citizenship: dialogues of inspiration in Paulo Freire}

\author{
Niño, infancia y ciudadanía: diálogos de inspiración en Paulo Freire
}

\author{
Marta Regina Paulo da Silva*
}

\section{Resumo}

O presente artigo problematiza a relação criança, infância e cidadania a partir de diálogos de inspiração em Paulo Freire. O intuito é o de apresentar as contribuições da epistemologia desse educador para pensar a constituição da cidadania da infância e a proposição de uma educação infantil cidadã. O diálogo parte dos resultados de uma pesquisa teórica, que investiga nas obras de Freire sua compreensão sobre as crianças, as infâncias e a educação das crianças pequenas. Em seus escritos, Freire denuncia as formas de opressão às quais estão submetidos meninos e meninas e o quanto o processo educativo revela-se autoritário e antidialógico, silenciando, assim, suas vozes. Esse autor defende as crianças como sujeitos de direitos, dentre eles o direito à palavra e à participação, propondo que as instituições de educação infantil se transformem em centros de criatividade, nos quais se ensine e se aprenda com alegria. O estudo conclui que a epistemologia freiriana nos remete à compreensão de que educação, cidadania e infância não são apenas conceitos abstratos, mas dimensões de uma práxis crítica e criativa, que nos possibilita reconhecer as crianças como cidadãs e construir com elas práticas pedagógicas emancipadoras.

Palavras-chave: infância; cidadania; Paulo Freire; participação; educação infantil.

\section{Abstract}

This article discusses the relationship between child, childhood and citizenship based on dialogues inspired by Paulo Freire. The aim is to present the contributions of this educator's epistemology to think about the constitution of childhood citizenship and the proposition of a citizen education. The dialogue starts from the results of a theoretical research that investigates in Freire's works his understanding about children, childhood and the education of young children. In his writings Freire denounces the forms of oppression to which boys and girls are subjected and how authoritarian and anti-dialogical the educational process is, thus silencing their voices. This author defends children as subjects of rights, including the right to speak and to participate, proposing that early childhood education institutions become centers of creativity in which to teach and learn with joy. The study concludes that Freire's epistemology leads us to the understanding that education, citizenship and childhood are not only abstract concepts, but dimensions of a critical and creative praxis that enables us to recognize children as citizens and build emancipatory pedagogical practices with them.

Keywords: childhood; citizenship; Paulo Freire; participation; early childhood education.

Recebido em: 15/10/2019 - Aprovado em 21/05/2021

http://dx.doi.org/10.5335/rep.v28i1.10088

Doutora em Educação pela Unicamp. Mestre em Educação pela Universidade Metodista de São Paulo (Umesp). Graduada em Pedagogia e Psicologia. Docente-Pesquisadora do Programa de Pós-Graduação em Educação da Universidade Municipal de São Caetano do Sul (PPGE-USCS). Coordenadora do Grupo de Estudos e Pesquisa Infâncias, Diversidade e Educação - GEPIDE (PPGE-USCS) e do Grupo de Estudos e Pesquisa Paulo Freire - GEPPF (PPGE-USCS). Orcid: https://orcid.org/0000-0002-8574-760X.E-mail: martarps@uol.com.br 


\section{Resumen}

Este artículo analiza la relación entre niño, infancia y ciudadanía a partir de diálogos inspirados en Paulo Freire. El objetivo es presentar las contribuciones de la epistemología de este educador para pensar sobre la constitución de la ciudadanía infantil y la propuesta de una educación ciudadana para los niños. El diálogo parte de los resultados de una investigación teórica que investiga en los trabajos de Freire su comprensión sobre los niños, la infancia y la educación de los niños pequeños. En sus escritos, Freire denuncia las formas de opresión a las que están sujetos los niños y las niñas y cuán autoritario y antidiálogo es el proceso educativo, silenciando así sus voces. El autor defiende a los niños como sujetos de derechos, incluido el derecho a la palabra y a participación, proponiendo que las instituciones de educación de la primera infancia se conviertan en centros de creatividad donde enseñamos y aprendemos con alegría. El estudio concluye que la epistemología de Freire nos lleva a comprender que educación, ciudadanía y infancia no son solo conceptos abstractos, sino dimensiones de una praxis crítica y creativa que nos permite reconocer a los niños como ciudadanos y construir com ellos prácticas pedagógicas emancipadoras.

Palabras clave: infancia; ciudadanía; Paulo Freire; participación; educación infantil.

\section{Introdução}

Desde o final da década de 1950, Paulo Freire (2001 [1959 $\left.{ }^{1}\right)$ já denunciava as relações autoritárias e antidialógicas às quais as crianças estavam submetidas. Esse educador pernambucano escrevia sobre o quanto tais experiências têm início nas famílias e se prolongam nas escolas silenciando meninos e meninas em sua curiosidade, em seu direito de se expressarem. Discutia, também, que a construção da autonomia exige experiências democráticas que são negadas às crianças, sendo necessária a revisão de atitudes das famílias e das instituições educacionais no sentido de ampliar cada vez mais a participação delas nos diferentes espaços sociais nos quais convivem.

Esse silenciamento das vozes infantis, presente ainda hoje em nossa sociedade, expressa uma das formas de opressão em que o adulto impõe sobre as crianças a sua leitura de mundo. Essa ação antidialógica, imposta pelo opressor, tem como uma de suas principais características o que Paulo Freire chamou de “invasão cultural" (FREIRE, 2003 [1970]). Invasão porque se trata de conquistar e dominar, não apenas econômica, mas culturalmente, negando àquele que é dominado o direito de dizer a sua palavra ao mesmo tempo em que desqualifica a sua cultura.

Nessa relação de dominação, o oprimido deve observar a realidade a partir da ótica do opressor, jamais da sua. Com isso, verificamos uma das ações mais desumanizantes, visto que nega a homens e mulheres a sua vocação ontológica de "ser mais", subestimando a sua capacidade de criação e recriação, e afogando neles e 
nelas o desejo de, curiosa e coletivamente, aventurarem-se no conhecimento de si, do outro e do mundo.

Como assevera Freire, a invasão cultural ocorre de diferentes formas e entre os diferentes atores sociais e dentre eles estão certamente as crianças. $\mathrm{Na}$ invasão cultural da infância intenta-se tornar inautêntico o agir, o pensar e o sentir das crianças, compreendendo-as tão somente como reprodutoras da cultura, cabendo, portanto, aos adultos prepará-las para o exercício da cidadania. Não se reconhece a criança como cidadã, mas como um "projeto", como um "vir a ser".

Nessa forma de invasão, busca-se frear a capacidade de criação de meninos e meninas, desqualificar a leitura que fazem do mundo e silenciar seus corpos. Como forma de "domesticação" intenta uma atitude de sujeição a uma determinada ordem social, negando, assim, as subjetividades e, consequentemente, a afirmação das crianças como agentes de criação e transformação.

No entanto, como discute Freire, a invasão cultural sempre irá se deparar com resistências. No caso das crianças, estas insistentemente questionam os currículos escolares, demonstrando, por meio de suas diferentes formas de expressão, que não "cabem" nas instituições educacionais historicamente construídas para elas, com práticas autoritárias e antidialógicas. Contra isso, meninos e meninas resistem. Como afirma o filósofo Ernani Maria Fiori, no prefácio de Pedagogia do Oprimido (FREIRE, 2003 [1970], p. 21), “[...] os dominados, para dizerem a sua palavra, têm que lutar para tomá-la. Aprender a tomá-la dos que a detêm e a recusam aos demais é um difícil, mas imprescindível aprendizado - é a "pedagogia do oprimido".

Segundo Freire (2003 [1970], p. 154, grifos do autor), renunciar à invasão cultural significa “[...] deixar de estar sobre ou 'dentro', como 'estrangeiros', para estar com, como companheiros". Romper com a invasão cultural da infância, significa compreender o mundo a partir dos olhos das crianças, o que implica na desconstrução da cultura do silêncio, e, por sua vez, na construção de uma relação dialógica com elas, reconhecendo-as como cidadãs e, portanto, como participantes ativas da e na sociedade. Se assim for, como afirma Tonucci (2005, p.18), “[...] a relação com elas será correta, entre cidadãos adultos e pequenos cidadãos, mas, agora, cidadãos". Do contrário, continuaremos a exclui-las e ficaremos excluídos de seus direitos, porque sempre serão "futuros cidadãos".

Desse modo, escutar as crianças, é reconhecer que precisamos delas, uma vez que são capazes de dar ideias, opiniões e fazer propostas; é considerar suas vozes nas decisões que envolvem suas vidas e também as nossas, seja no âmbito familiar, 
escolar ou na comunidade, visando a construção de uma sociedade mais democrática, mais justa e mais humana.

Nesse sentido, este artigo apresenta o aporte teórico de Paulo Freire para pensar esta criança cidadã e o seu direito à participação política na sociedade e, em especial, no interior das instituições de educação infantil. A reflexão acerca das contribuições desse autor é resultado da pesquisa intitulada "Crianças e Infâncias em Paulo Freire”, desenvolvida no Grupo de Estudos e Pesquisa Paulo Freire do Programa de Pós-Graduação em Educação da Universidade Municipal de São Caetano do Sul. Trata-se de uma pesquisa de natureza teórica, cujo objetivo é o de investigar nas obras desse educador sua compreensão sobre as crianças e as infâncias e, nessa perspectiva, como sua epistemologia pode contribuir para (re)pensar a educação das crianças. Por obra definimos, para efeitos desta investigação, os livros desse autor publicados em português, que foram organizados em cinco períodos como uma forma de melhor compreender o contexto de sua produção ${ }^{2}$. Como procedimento metodológico, temos realizado nas leituras o rastreamento das palavras: criança, infância ou expressões que remetem a estes universos.

O momento atual é propício para nos debruçarmos sobre a epistemologia e a vida educadora desse educador, visto vivermos um período de recrudescimento das formas de violência contra mulheres, negros, negras, indígenas, comunidade LGBTQI+ e, é claro, as crianças, as que mais sofrem com o desmantelamento das políticas públicas e das conquistas sociais e históricas resultantes das muitas lutas travadas pelo povo brasileiro. Assim, em um período em que as forças conservadoras buscam amordaçar e silenciar estudantes, docentes, pesquisadores e pesquisadoras, a atualidade do pensamento de Paulo Freire nos convoca à necessidade política de reinventá-lo, de modo a responder aos desafios de nosso tempo histórico. Posto isso, que o diálogo apresentando neste artigo possa inspirar o (re)pensar a relação criança, infância e cidadania e, nela, a proposição de uma educação infantil cidadã.

\section{Criança: cidadã?}

O reconhecimento da criança como sujeito de direitos é muito recente na legislação brasileira, tendo sua origem na promulgação da Constituição federal brasileira (BRASIL, 1988), fruto de intensas lutas dos movimentos sindicais, feministas, das mulheres, estudantis, populares que ganharam força, sobretudo na década de 1980, e passaram a reivindicar melhores condições de vida, de trabalho, de edu- 
cação. Desse documento, desdobram-se outras leis que reafirmam os direitos das crianças, dentre elas o Estatuto da Criança e do Adolescente (ECA) (BRASIL, 1990), que trata da participação da criança na vida familiar, comunitária e política, e o seu direito à opinião e à expressão; a Lei de Diretrizes e Bases da Educação Nacional (LDBEN) (BRASIL, 1996), que reconhece o direito à Educação Infantil ao inseri-la como primeira etapa da Educação Básica; as Diretrizes Curriculares Nacionais para a Educação Infantil (DCNEI) (BRASIL, 2010), que reafirmam tais direitos e explicitam os princípios para a educação das crianças pequenas, sendo eles:

- Éticos: da autonomia, da responsabilidade, da solidariedade e do respeito ao bem comum, ao meio ambiente e às diferentes culturas, identidades e singularidades.

- Políticos: dos direitos de cidadania, do exercício da criticidade e do respeito à ordem democrática.

- Estéticos: da sensibilidade, da criatividade, da ludicidade e da liberdade de expressão nas diferentes manifestações artísticas e culturais (BRASIL, 2010, p. 16).

As conquistas observadas nessa legislação legitimam-se em documentos de maior abrangência como: a Declaração Universal dos Direitos da Criança (ONU, 1959) e a Convenção Mundial dos Direitos da Criança (ONU, 1989). Segundo Sarmento, Fernandes e Tomás (2007, p. 192):

A Convenção sobre os Direitos da Criança assim como toda a legislação e instrumentos jurídicos que se reporta às crianças, apesar de todas as limitações e críticas, é uma marca de cidadania, um sinal da capacidade que as crianças têm de serem titulares de direitos e um indicador do reconhecimento da sua capacidade de participação.

A afirmação de meninos e meninas como sujeitos de direitos resulta de uma nova compreensão da criança como um ser potente, agente ativo no meio em que vive, que lê e comunica o mundo de um modo muito singular e que produz cultura. Resulta ainda da compreensão de sua educação para além dos contextos familiares, envolvendo nesse processo as diferentes instituições da sociedade, dentre elas as educacionais.

Criança e infância são categorias construídas historicamente, o que significa dizer que, a compreensão sobre elas foi se modificando ao longo da história em função dos diferentes contextos sociais, político-econômicos e culturais nos quais estavam inseridas. Desta maneira, capturadas pelos discursos médico, psicológico, 
pedagógico e sociológico tiveram sua imagem aprisionada à compreensão de uma “[...] infância universal e um padrão de criança definido pelos critérios de idade, de dependência em relação ao adulto, em função de uma fragilidade física e psicológica, e o seu desenvolvimento através de etapas sucessivas. Uma criança a-histórica e reprodutora da cultura do adulto" (FARIA; GOBBI; SILVA, 2017, p. 17).

Desconstruir essa imagem da criança como um ser da "falta" e da infância como uma etapa passageira do desenvolvimento humano vem sendo um processo lento e gradativo. Com isso, apesar do reconhecimento da criança como um ser potente e de direitos, seja na legislação seja nos estudos sobre a infância, a imagem da criança como um "vir a ser" ainda se faz bastante presente no interior das instituições educacionais, configurando-se como um dos desafios à prática pedagógica. Ora, mas se reconhecer a criança como um ser potente, não apenas no discurso, mas na sua cotidianidade, já tem se desvelado um processo moroso, mais desafiador ainda tem sido o seu reconhecimento como cidadã. Afinal, será a criança cidadã? Quando nasce um/a cidadão/cidadã?

Qvortrup (2010) chama nossa atenção para as atitudes ambíguas de nossa sociedade para com as crianças e para a relação entre elas e a política, com destaque para as formas de proteção às quais meninos e meninas estão submetidos e que terminam por afastá-los dos adultos e de assuntos referentes à economia e à política, 0 que considera como uma atitude "irrealista", uma vez que entre "[...] outras razões, isto é provado pelo fato de que as crianças são parte de um projeto que faz delas a matéria para a construção do futuro" (2010, p. 790). Para o autor, se, por um lado, busca-se proteger as crianças do mundo adulto, separando-as desse mesmo mundo, por outro, há uma indiferença ou desatenção a elas no desenvolvimento político e econômico da sociedade, o que as coloca como o grupo geracional mais afetado pelas desigualdades sociais.

Essa exclusão da participação das crianças da vida política também é debatida por Sarmento, Fernandes e Tomás (2007, p. 184): “O confinamento da infância a um espaço social condicionado e controlado pelos adultos produziu, como consequência, o entendimento generalizado de que as crianças estão «naturalmente» privadas do exercício de direitos políticos", o que as torna “[...] o único grupo social verdadeiramente excluído de direitos políticos expressos". Essa exclusão termina por invisibilizar meninos e meninas enquanto "atores políticos concretos" e, consequentemente, impacta nas decisões políticas das gerações futuras.

A participação política das crianças é um imperativo para a cidadania da infância. Contudo, ela está condicionada, mas não pré-determinada, às estruturas 
sociais, políticas, econômicas e culturais em que se encontram meninos e meninas. Sabemos que o conceito de cidadania é uma construção social e, como tal, está vinculado ao contexto no qual foi engendrado. Desse modo, ao analisarmos a realidade brasileira marcada por uma história de escravidão, elitismo e exclusão, em que a "[...] relação de forças que se estabelece entre grupos com interesses distintos e antagônicos, esse conceito, como tantos outros, acaba se tornando categoria que expressa a posição do projeto hegemônico" (BARBOSA; ALVES; MARTINS, 2008, p. 4).

Nesse projeto, cidadania se restringe aos adultos, sendo as crianças excluídas em função do fator idade, uma vez que permanece ainda fortemente no imaginário social a compreensão da criança como um ser imaturo, frágil, dependente, que deve ser preparado para a vida adulta. Para Sarmento, Soares e Tomás (2004, p. 1), é esse “[...] conjunto de características bio-psicológicas que supostamente não outorgam à criança o conjunto de competências que os adultos consideram necessárias para o exercício da cidadania”.

Outro fator que coaduna com essa exclusão da criança diz respeito a certa compreensão de cidadania como algo pronto, acabado, cujo status de cidadão/cidadã se adquire quando adulto, quase que como em um passe de mágica. A esse respeito, Barbosa, Alves e Martins (2008, p. 4, grifos das autoras) asseveram que:

Quando se trata da infância, a cidadania parece ser colocada como projeto futuro: "a criança de hoje é [será] a cidadã de amanhã". Ou seja, é como se a cidadania desabrochasse no adulto (bem) educado e ajustado às normas e padrões sociais. Porém, aqui não deixa de haver uma abstração do termo "cidadania": algo pronto a ser dado em algum momento e em situações nos quais o sujeito recebe um título socialmente concedido.

A cidadania não é algo pronto e não se dá a partir de uma determinada idade. Como seres inacabados, cuja vocação ontológica é a de "ser mais" (FREIRE, 2003 [1970]), lemos e comunicamos o mundo desde que nascemos e, nesse processo, vamos nos constituindo como cidadãos/cidadãs. Desse modo, embora o reconhecimento legal dos direitos das crianças seja uma conquista fundamental, ele não é suficiente; é preciso também criar condições para o seu exercício por meio da participação ativa das crianças nas diferentes esferas da sociedade, a qual é aprendida nas práticas cotidianas, constituindo-se em uma aprendizagem que nos acompanha ao logo da vida.

Nesse processo, há que se respeitar a razão infantil, ou seja, a visão de mundo das crianças, compreendendo-a como a faculdade humana que elas possuem de criar estruturas ideativas a partir de suas impressões, sentimentos e compreen- 
sões do seu entorno. Na razão infantil não há uma hierarquização das linguagens, uma vez que ela se efetiva por diferentes formas de expressão em que a corporeidade não fragmenta as sensações, as emoções e a cognição (SILVA; FASANO, 2020). Sendo assim, meninos e meninas são capazes de intervir no mundo, expressando suas ideias, escolhas, opiniões e fazendo propostas a respeito de todos os problemas que se colocam em seu cotidiano, isso porque "[...] elas também ali vivem, como cada cidadão, e ali vivem a partir de seu próprio ponto de vista particular que é, ao mesmo tempo, mais 'baixo' e mais ignorado do que o dos outros” (TONUCCI, 2005, p. 20-21, grifos do autor).

A cidadania da infância, ao defender o direito de participação política das crianças, não minimiza a importância das medidas de proteção e provisão, que devem ser garantidas pela família e Estado. De acordo com Soares (2005, p. 35-36, grifos da autora):

Direitos de provisão - implicam a consideração dos programas que garantam os direitos sociais da criança, nomeadamente 0 acesso de todas as crianças a direitos como a saúde, educação, segurança social, cuidados físicos, vida familiar, recreio e cultura;

Direitos de proteç̧ão - implicam a consideração de uma atenção distinta às crianças, de um conjunto de direitos acrescidos, que, por motivos diversos, nomeadamente situações de discriminação, abuso físico e sexual, exploração, injustiça e conflito, se encontrem privadas ou limitadas no exercício dos seus direitos;

Direitos de participação - implicam a consideração de uma imagem de infância activa, distinta da imagem de infância objecto das políticas assistencialistas, à qual estão assegurados direitos civis e políticos, ou seja, aqueles que abarcam o direito da criança a ser consultada e ouvida, o direito ao acesso à informação, à liberdade de expressão e opinião e o direito a tomar decisões em seu benefício, que deverão traduzir-se em acções públicas para a infância, que consideram o ponto de vista das crianças.

A compreensão da indissociabilidade destes direitos: provisão, proteção e participação é fundamental, pois reconhecer a criança como um sujeito capaz de participar das decisões referentes à sua vida, não significa negar a necessidade de cuidados e proteção. Sobre essa indissociabilidade, Soares (2005) discute os paradigmas da criança dependente, emancipada e participativa como formas de compreensão do exercício dos direitos de meninos e meninas. Segundo essa pesquisadora, os paradigmas da criança dependente e da criança emancipada se apresentam com posições quase que incompatíveis, em um movimento que oscila entre "[...] o proteccionismo exacerbado e a emancipação das crianças" (2005, p. 42), enquanto que o terceiro, o da criança participativa, "[...] recupera a ideia de interdependência do exercício dos direitos, considerando que os direitos de protecção e participação 
não são incompatíveis (2005, p. 42). Contudo, como ressaltam Sarmento e Pinto (1997), desses três direitos, não se observam avanços no que diz respeito ao direito à participação, seja na construção de políticas seja na organização das instituições educacionais.

Freire (2001 [1993]), ao defender a participação, também alerta para o caráter indissociável entre participação e proteção. Ao propor que as cidades estimulem as suas várias instituições sociais a se empenharem em campanhas que tenham por objetivo desafiar crianças, jovens e adultos a refletirem sobre o direito de ser diferente, adverte que essa discussão deva ocorrer "[...] sem que isto signifique correr o risco de ser discriminado, punido ou, pior ainda, banido da vida" (2001 [1993], p. 26).

O direito de ser diferente afirma nossa vocação para "ser mais", estando esta condicionada pelo contexto social, político, econômico e cultural no qual estamos inseridos. Com isso, no aprendizado da democracia, Freire (2003 [1994], p. 203) ressalta alguns aspectos que devem ser "política e pedagogicamente tratados":

A luta, no Brasil, pela democracia, passa por uma série de possíveis ângulos a ser política e pedagogicamente tratados - o da justiça, sem a qual, não há paz, o direitos humanos, o do direito à vida, que implica o de nascer, o de comer, o de dormir, o de ter saúde, o de vestir, o de chorar os mortos, o de estudar, o de trabalhar, o de ser crianças, o de crer ou não, o de viver cada um e cada uma a sua sexualidade como bem lhe aprouver, o de criticar, o de discordar do discurso oficial, o de ler a palavra, o de brincar não importa a idade que se tenha, o de ser eticamente inconformado do que ocorre no nível local, no regional, no nacional e no mundial.

Ao afirmar o direito de as crianças serem crianças, Freire chama a atenção para as muitas crianças que têm sido expropriadas destes tantos direitos, em especial aquelas das classes populares, seja pela condição de pobreza, fruto das grandes desigualdades sociais, seja pela cor de sua pele, gênero, idade, etnia.

Cabe ressaltar que as enormes desigualdades e a discriminação contra e entre as crianças assentam-se na estrutura social. Desse modo, não se pode deixar de considerar a interdependência dos diferentes direitos. Defender o direito à educação, por exemplo, implica, necessariamente, segundo Arroyo (2015, p. 20), defender o "[...] direito à vida, trabalho, terra, território, teto, identidades, igualdade, diversidade, justiça... direitos atrelados a outro projeto de sociedade, de campo, de cidade, de padrão de trabalho e de poder".

Assegurados na forma de Lei, estão os direitos à vida, à saúde, à liberdade, ao respeito, à dignidade, à convivência familiar e comunitária, à educação, à cultura, ao esporte e ao lazer, à proteção. Entretanto, nesse mundo ao avesso, como denuncia Galeano (1999), há mais de vinte anos, é negado às crianças o direito de 
serem crianças, de brincar, não trabalhar, contar suas histórias, criar, imaginar. Crianças, ricas ou pobres, todas confinadas aos valores do mercado, todas fadadas à solidão. Solidão, como afirma Tonucci (2008), que se caracteriza como uma doença social que atinge crianças e adultos. Ambos presos em sua "casa fortaleza", pois lá fora, na cidade, há muitos perigos; instaurado o medo, a cidade já não pertence mais aos sujeitos e, em especial, às crianças. Também não lhes pertence mais o tempo e espaço só para si, em que possam criar, brincar, sujar-se, divertir-se, não fazer nada.

Defender, portanto, a participação infantil significa compreender não apenas a potencialidade das crianças, mas também sua vulnerabilidade, e protegê-las, sem com isso (ou em nome disso) sufocar seu direito de dizerem sua palavra, de se expressarem livremente, visto que, esse direito "[...] deve incluir a liberdade de procurar, receber e divulgar informações e ideias de todo tipo, independentemente de fronteiras, seja verbalmente, por escrito ou por meio impresso, por meio das artes ou por qualquer outro meio escolhido pela criança" (ONU, 1989, não paginado).

Como sujeitos de criação e não da pura adaptação, a presença das crianças nas diferentes instâncias sociais, através de suas resistências, transgressões e afirmando-se como sujeito de direitos, pressiona a (re)invenção das instituições educativas e nelas a construção de outras identidades docentes.

\section{Por uma educação infantil cidadã}

Um dos ensinamentos de Paulo Freire é o de que a educação deve ser construída com os educandos e as educandas, a partir de uma relação dialógica. No caso da educação infantil, embora verifiquemos uma concepção mais afirmativa da criança e da infância nos documentos legais e nas pesquisas da área, observamos ainda, em muitas instituições, um abismo entre o discurso e as práticas educativas construídas para as crianças pequenas. Em sua maioria, revelam uma educação bancária, fundamentalmente narradora, nas quais podemos notar falas sobre conteúdos "mortos" que não se referem à realidade das crianças, sendo-lhes alheios à sua experiência existencial, e que, portanto, não se trata de uma educação que objetive uma ação transformadora, mas apenas a fixação, a memorização e a repetição.

Dentre essas práticas, encontram-se aquelas que priorizam a memorização do sistema alfabético e numérico, a cópia e repetição de palavras ou até mesmo sílabas, no intuito de preparar as crianças para o ensino fundamental; ou ainda, aquelas que didatizam as brincadeiras, reafirmando um modelo escolar hegemô- 
nico que não valoriza a curiosidade, a inventividade, as múltiplas linguagens das crianças e suas produções culturais. Tais práticas são reveladoras de uma história em que pouco se olhou para o mundo das crianças a partir dos seus olhos, mas sim a partir da maneira como o adulto via/vê o mundo das crianças. Desconstruir tais práticas implica reconhecer a criança em sua alteridade, uma vez que:

[...] a infância nunca é o que sabemos (é o outro dos nossos saberes), mas, por outro lado, é portadora de uma verdade à qual devemos nos colocar à disposição de escutar; nunca é aquilo apreendido pelo nosso poder (é o outro que não pode ser submetido), mas ao mesmo tempo requer nossa iniciativa; nunca está no lugar que a ela reservamos (é o outro que não pode ser abarcado), mas devemos abrir um lugar para recebê-la. Isso realmente é aceitar a criança como um outro (LARROSA, 2003, p. 186).

Receber a criança como um outro passa por compreender a infância para além de uma etapa passageira do desenvolvimento humano, mas como um tempo social importante em si mesmo e que nos acompanha na vida adulta, o que nos remete a pensá-la como a própria condição da existência humana. Sendo assim, ela não é apenas cronologia.

Encontramos essa compreensão da infância em Paulo Freire, esse educador que se autodenominou como um "menino conectivo", um homem que não deixou morrer o menino que foi e que não pôde ser. Em suas palavras: "Eu acho que uma das coisas melhores que eu tenho feito na minha vida, melhor do que os livros que eu escrevi, foi não deixar morrer o menino que eu não pude ser e o menino que eu fui, em mim" (FREIRE, 2001, p. 101).

Essa sua conexão com a infância, sobretudo quando relata suas próprias experiências, denota uma imagem mais afirmativa da infância, “[...] a infância como algo que o amadurecimento faria bem em preservar, alimentar e cuidar na medida em que outorga vida à vida e, por isso, nunca deve abandonar-se" (KOHAN, 2018, p. 10).

A infância, desde essa perspectiva, ao desconstruir a ideia de se tratar apenas de uma etapa passageira do desenvolvimento, desconstrói também a compreensão da criança como um ser da "falta", pois, como afirma Agamben (2005), a ausência de voz (en-fant) não significa uma falta, e sim uma condição, visto ser na infância que nos constituímos como sujeitos na e pela linguagem. De acordo com esse filósofo:

[...] a infância que aqui está em questão, não pode ser simplesmente algo que precede cronologicamente a linguagem e que, a uma certa altura, cessa de existir para versar-se na palavra, não é um paraíso que, em um determinado momento, abandonamos para sempre a fim de falar, mas coexiste originalmente com a linguagem, constitui-se aliás ela mesma na expropriação que dela efetua, produzindo a cada vez o homem como sujeito (2005, p. 59). 
Segundo Agamben (2005), a condição de "en fant" é o que nos torna abertos ao mundo, transformando, no cotidiano, a língua em discurso capaz de nos colocar na situação de criadores de cultura. Desse modo, porque somos não falantes e nos construímos como falantes há história. $\mathrm{E}$ porque os falantes continuam infantes e continuam também, permanentemente, aprendendo a falar e a serem falados, a historicidade do ser humano segue fazendo-se. Assim, se para Agamben há história porque há infância, para Freire há infância devido à condição de inacabamento do ser humano. Não é possível falar em infância sem a consciência de nossa condição de seres inacabados, ao mesmo tempo em que tal condição, para não ser estéril, solicita de nós a capacidade de criar nosso agir no mundo molhado da nossa condição infantil (SANTOS NETO; SILVA, 2006).

Nesse sentido, compreendemos que é preciso olhar e escutar esta infância, ou seja, mantê-la viva. A infância das crianças e a nossa enquanto educadores e educadoras, para que possamos em nossa docência construir uma pedagogia curiosa, que pergunta e se pergunta constantemente, e que reconheça que meninos e meninas são portadores "de uma verdade" que precisa ser escutada. Que nesse processo possamos viver uma vida educadoramente infantil, aquela que, inquieta, incansável, esperançosa está disposta a recomeçar, pois, de acordo com Kohan (2020, p. 98) "[...] a infância que educa não tem idade nem se mede pela passagem das horas, dos dias, dos anos... a infância educa em outro tempo, um tempo próprio... de presença e presente. Um tempo infantil. [...]. Um tempo de pura presença".

E aqui encontramos o tempo da criança, o tempo presente e de presença. Um tempo presente de um eterno recomeçar. Um tempo de intensidade. Meninos e meninas são seres ativos e na relação com o mundo humanizam-se ao mesmo tempo em que também humanizam o mundo; portanto, não se entregam passivamente à lógica adultocêntrica, mas se envolvem nos processos de socialização, lendo o mundo a partir de suas experiências existenciais e, no exercício da dialogicidade, produzem as culturas infantis que, se devidamente consideradas, podem levar a cultura estabelecida historicamente pelos adultos a ser repensada e ser reinventada e, com isso, construir pedagogias das infâncias com as crianças e não para as crianças.

Nesse contexto, a participação das crianças é imprescindível para cidadania da infância. Isso porque a cidadania só se concretiza quando os sujeitos participam ativamente visando à transformação da sociedade. Para Freire, o ser humano é participante ativo na construção histórica de seus direitos, tendo a educação uma importante contribuição na formação dos cidadãos e cidadãs. Vale destacar que esse educador, sem superestimar o papel da educação, defende sua relevância na 
construção de uma cidadania ativa. Segundo ele, sobre a relação dialética entre educação e cidadania:

Não dá para dizer que a educação crie a cidadania de quem quer que seja. Mas, sem a educação, é difícil construir a cidadania. A cidadania se cria com uma presença ativa, crítica, decidida, de todos nós com relação à coisa pública. Isso é dificílimo, mas é possível. A educação não é a chave para a transformação, mas é indispensável. A educação sozinha não faz, mas sem ela também não é feita a cidadania (1995, p. 74).

Importante pontuar que, para o autor, o papel que a educação possui no processo de transformação social não se baseia em um certo idealismo que não leva em conta os contextos históricos e as condições socioculturais em que estão imersos homens e mulheres, mas na sua profunda crença na capacidade dos seres humanos, em colaboração, ao desvelar o mundo, transformá-lo. Assim, faz parte desse processo o sentido da crítica e dos conflitos, sendo esses inerentes ao espaço público. A participação, portanto, é fundamental no processo de libertação, visto que, nas palavras de Freire (2003, [1970], p. 90): “[...] a existência humana não pode ser muda, silenciosa, nem tampouco pode nutrir-se de falsas palavras, mas de palavras verdadeiras, com que os homens [e mulheres] transformam o mundo". Esse processo se inicia desde a mais tenra idade e tem na escola democrática uma instância importante para seu exercício (FREIRE, 1993).

A criança compreendida por Freire é potente, curiosa, criativa, perguntadeira, e precisa ser estimulada pelo educador e pela educadora de modo a ir:

[...] descobrindo a relação dinâmica, forte, viva, entre palavra e ação, entre palavra-ação-reflexão. Aproveitando-se, então, exemplos concretos da própria experiência dos alunos durante uma manhã de trabalho dentro da escola, no caso de uma escola de crianças, estimulá-los a fazer perguntas em torno da sua própria prática e as respostas, então, envolveriam a ação que provocou a pergunta. Agir, falar, conhecer estariam juntos (FREIRE; FAUNDEZ, 2017 [1985], p. 72).

Meninos e meninas têm o direito de participar ativamente dos processos educativos em uma relação horizontal, o que não significa a negação da autoridade do educador, da educadora e nem a compreensão de que docentes e crianças são iguais; ao contrário, afirmamos com isso a posição democrática entre eles e elas, em que cada um conserva e defende sua identidade e em diálogo aprendem em comunhão. Em Pedagogia do oprimido, Freire (2003 [1970], p. 81) afirma que:

Ao fundar-se no amor, na humildade, na fé nos homens, o diálogo se faz uma relação horizontal, em que a confiança de um pólo no outro é consequência óbvia. [...]. Se a fé nos homens é um dado a priori do diálogo, a confiança se instaura nele. A confiança vai fazendo os sujeitos dialógicos cada vez mais companheiros na pronúncia do mundo. 
Uma relação dialógica com as crianças pressupõe acreditar nelas, confiar em sua capacidade de ler o mundo e de dizer a sua palavra a partir de suas diversas formas de expressão. Por essa razão, Freire defende que o educador e a educadora devem estimular o gosto das crianças pelas artes, pelos meios de comunicação, pela leitura e escrita. Que respeitem nelas o seu brincar. A expectativa é a de que elas avancem em seu conhecimento do mundo e que o façam de maneira participativa e investigativa. E para que isso seja respeitado e considerado na prática educativa, é preciso que educador e educadora se coloquem também em uma posição aprendente, isto é, de modo que possam aprender com o aprendizado da própria criança.

Aprender com a criança e com a infância...esta reflexão nos remete à Pedagogia da Autonomia.... Em Pedagogia da Autonomia, um dos saberes necessários à prática educativa apresentado por Freire (1997 [1996], p. 23) é o de que "não há docência sem discência", pois enquanto ensinam, educador e educadora também aprendem. E aprendem na relação com seus educandos e educandas mediatizados pelo mundo, visto serem estes e estas sujeitos de sua própria formação e não objetos. Assim, para Freire, o educador e a educadora progressistas não podem exercer uma pedagogia imobilizante, que se constitua em mera transferidora de conteúdos curriculares.

A criança, sujeito de sua formação, deve ser respeitada como tal. Escutar suas vozes constitui-se em um saber essencial à educação como prática da liberdade. Freire, acerca da ação antidialógica e autoritária da escola, relata a conversa com um grupo de estudantes de uma escola de primeiro grau (hoje, ensino fundamental) em que um dos educandos afirmava a necessidade de se escutar sempre as crianças sobre o que lhes é ensinado. Dizia o estudante: "Nunca nos perguntaram sobre o que queremos aprender. Pelo contrário, sempre dizem o que a gente deve estudar" (FREIRE; GUIMARÃES, 1984, p. 77). Freire pontua dessa experiência o fato de que meninos e meninas quando chegam às escolas têm algo a dizer e não apenas a escutar, sendo assim, é preciso escutá-los não importando a idade que tenham.

O reconhecimento da importância da escuta das crianças está presente no discurso de muitos educadores e educadoras, motivado, sobretudo, por estudos e pesquisas da área da infância. Contudo, quando observamos o cotidiano de creches e pré-escolas verificamos, em muitas destas instituições, uma prática pedagógica esvaziada de sentido, pois nelas não há escuta e, consequentemente, não há diálogo. O que se nota é um discurso sobre a realidade. Como meio de buscar coerência entre o discurso e a prática entendemos que retomar a concepção freiriana de diálo- 
go, escuta e amorosidade, pode contribuir no sentido de ressignificar tais conceitos e com isso (re)pensar sua materialidade no cotidiano da educação infantil.

Como já mencionado neste texto, o diálogo é o encontro entre os seres humanos que, mediatizados pelo mundo, o pronunciam, o que remete a uma profunda crença neles e em sua capacidade de ler e dizer o mundo. É, portanto, a força propulsora de um pensar crítico, que ao problematizar a realidade objetiva transformá-la. Nesse sentido, como uma "exigência existencial" não pode ser reduzido ao depósito de ideias de um sujeito sobre outro, como se verifica em perspectivas antidialógicas, bancárias, nas quais as crianças são vistas como um futuro adulto, que precisa se adaptar a uma sociedade pensada e construída pelos adultos para elas e não com elas.

O diálogo implica necessariamente em humildade e abertura, reconhecendo que ninguém sabe tudo e que ninguém sabe nada, mas que nesse encontro somos capazes de saber mais. No caso da educação infantil, isso exige escutar as crianças. Escuta que solicita silêncio por parte do educador e da educadora, o que não significa omissão ou abandono, mas um profundo respeito à capacidade e às formas pelas quais as crianças pensam e agem no mundo (SILVA, 2017).

O silêncio, enquanto um valor educativo, possibilita que meninos e meninas possam dizer a sua palavra a partir de suas múltiplas linguagens. Cabe ressaltar que a palavra em Freire reveste-se do sentido de dizer o mundo e agir sobre ele, portanto, uma práxis social que nos impele ao compromisso com o processo de humanização de todos e todas. Nesse processo, o aprendizado da escuta se faz essencial, pois é escutando as vozes das crianças que aprendemos a falar com elas, visto que, "Somente quem escuta paciente e criticamente o outro, fala com ele, mesmo que, em certas condições, precise falar a ele. O que jamais faz quem aprende a escutar para poder falar com é falar impositivamente" (1997 [1996], p. 127).

A escuta, o diálogo, demandam um querer bem às crianças e ter a coragem de dizê-lo, de falar de amor por elas enquanto compromisso não apenas técnico, mas também ético, político e estético (FREIRE, 1993, 1997 [1996]). Nesse sentido, educar dialogicamente é um ato de amor, é um comprometer-se consigo e com o outro na luta pela libertação de todos e todas. A amorosidade, portanto, refere-se à radicalidade de uma exigência ética, visto caracterizar-se como uma intercomunicação entre duas consciências que se respeitam e que têm um profundo compromisso uma com a outra. Daí o fato de Freire afirmar que não há diálogo se não houver um profundo amor ao mundo e aos homens e mulheres. Trata-se, deste modo, de 
um "amor armado", um "[...] amor brigão de quem se afirma no direito ou no dever de ter o direito de lutar, de denunciar, de anunciar" (1993, p. 57).

A defesa e a concretude de uma educação emancipadora na educação infantil implicam em oferecer, desde os berçários, espaços e atividades em que os bebês e as crianças pequenas possam fazer escolhas, tomar decisões, explorar, descobrir, perguntar, perguntar-se, narrar, debater, dizer sua palavra, participar. Nesse sentido, encontramos em Freire pistas para pensarmos a materialização dessa participação, que deve partir da cotidianidade das crianças e considerar suas várias formas de ler e comunicar o mundo.

Em diálogo com o educador Sérgio Guimarães, Freire defende o brincar como linguagem fundamental da infância, como o modo pelo qual meninos e meninas vão se desvelando, apropriando-se e confrontando-se com o mundo em que vivem (FREIRE; GUIMARÃES, 1984). O brincar constitui-se como espaço de ação e de compreensão da criança sobre a realidade; um espaço de descobertas e de aprendizagens. Em outro diálogo, discorrendo sobre os recursos da escola pública, os autores pontuam:

[...] eu acho que o problema não é tanto porque sejam pedrinhas e tampinhas de garrafa. Acho que isso poderia dar uma excelente educação, se a escola realmente fosse capaz, como política, de aproveitar os recursos naturais, aqueles fragmentos de mundo com que as crianças brincam, por exemplo. Seria exatamente a partir da brincadeira delas com esses pedaços de coisas e com essas coisas, que elas poderiam compreender a razão de ser das próprias coisas (FREIRE; GUIMARÃES, 1982, p. 47).

Neste diálogo, Freire defende que a espontaneidade, a imaginação, a expressividade, a inventividade e a criatividade das crianças não devem ser negadas "[...] em nome da instalação de uma cega disciplina intelectual" (FREIRE; GUIMARÃES, 1982, p. 53). No entanto, isso não significa a ausência de uma intencionalidade pedagógica que, em Freire, intenta a ampliação da leitura de mundo pela criança, uma leitura que possa ir se fazendo cada vez mais crítica.

Deste modo, o papel do educador e da educadora não é o de discursar sobre a realidade mostrando às crianças o que ela é, segundo seu olhar adulto, mas instigar a curiosidade para que elas possam, de maneira ativa, criativa e coletiva, desvelar a realidade e transformá-la. Aqui caberia aos(às) docentes respeitar as diferentes leituras, as diferentes compreensões e opiniões, sem, contudo, deixar de dizer também a sua palavra. Freire assevera que o educador "[...] tem que ter a coragem de dizer aos meninos como é que ele pensa também, desde que respeite a diferença entre ele e os meninos. O que vale dizer: desde que exercite a tolerância, que é, em curta análise, o respeito à diferença" (FREIRE; GUIMARÃES, 1984, p. 18). 
Nesse movimento dialético de leitura de mundo, uma outra pista diz respeito às perguntas, pois para Freire, o ato de conhecer começa com o perguntar; são as perguntas que instigam a busca pelas respostas. Para esse educador, "[...] é possível e é preciso fazer com as crianças um tipo de educação criadora, desinibidora, uma educação que não se limite, nas crianças, o direito de perguntar; uma educação que, inclusive, sugira na prática, à criança, que ela jamais morra como criança" (VANNUCCHI; SANTOS; FREIRE, 1983, p. 69).

A educação, de um modo geral, é uma educação das respostas e não das perguntas. Ao denunciar a pedagogia das respostas, que ainda marcam muitas de nossas instituições educacionais, Freire alerta que:

[...] a repressão à pergunta é uma dimensão apenas da repressão maior - a repressão ao ser inteiro, à sua expressividade em suas relações no mundo e com o mundo. O que se pretende autoritariamente com o silêncio imposto, em nome da ordem, é exatamente afogar nele a indagação (FREIRE; FAUNDEZ, 2017 [1985], p. 68).

Construir uma relação dialógica com meninos e meninas, reconhecendo-os como participantes ativos da e na sociedade implica compreender o mundo a partir dos seus olhos. Para tanto, é preciso criar com elas o hábito de perguntar, de se espantar; de viver a pergunta, a indagação; de instigar a curiosidade pelo mundo físico e social. Concordando com Freire, a pedagogia da resposta é uma "[...] pedagogia da adaptação e não da criatividade. Não estimula o risco da invenção e da reinvenção. [...] negar o risco é a melhor maneira que se tem de negar a própria existência humana" (FREIRE; FAUNDEZ, 2017 [1985], p. 75).

Como nos constituir cidadãos/cidadãs sem indagarmos e nos indagar? Sem correr riscos? Sem sonhar a reinvenção de um outro mundo possível? Sem resistir às formas de opressão? Sem lutar? É preciso conhecer a realidade para transformá-la e o ato de conhecer inicia-se pelas perguntas. Assim, temos que romper com o silêncio imposto e em seu lugar construir um movimento de perguntar e perguntar-se, em que a dialogicidade, a amorosidade e a ludicidade constituam-se como dimensões fundamentais à participação das crianças e à construção de uma educação infantil cidadã.

Cidadã porque reconhece as crianças como cidadãs hoje, com direito à participação, provisão e proteção. Cidadã, pois, com clareza de seu compromisso ético e político na construção de uma educação emancipadora, faz-se e refaz-se no exercício cotidiano da cidadania, em um espaço coletivo de diálogo e partilha, não sendo este, portanto, um conceito abstrato e esvaziado de sentido. Cidadã porque ao reconhecer tal compromisso, luta para que todas as crianças e também seus educadores 
e educadoras aprendam e, assim, construam conhecimentos que os possibilitem ter uma vida digna, o que coloca o desafio de romper com práticas pedagógicas padronizadas e homogêneas. Cidadã, sobretudo, porque em um movimento inquietante de perguntar e perguntar-se exercita a cidadania no dia a dia, no agora e não como uma promessa de um tempo que talvez chegará. Crianças e adultos constituem-se cidadãs/cidadãos na concretude da vida e, sendo assim, é preciso que essa cidadania ativa seja instigada, (re)criada e (re)conquistada todos os dias.

\section{Considerações finais}

A epistemologia de Paulo Freire nos remete à compreensão de que educação, cidadania e infância não são apenas conceitos abstratos, mas dimensões de uma práxis crítica e criativa, que nos permite reconhecer as crianças como cidadãs e com elas construir práticas pedagógicas emancipadoras. Práticas estas com abertura suficiente para termos com elas um olhar de respeito a suas singularidades, suas necessidades e seus direitos, dentre estes, o direito a dizer sua palavra e a participar das decisões que envolvem suas vidas.

Concordamos, assim, com Freire quando ele afirma que a educação tem papel fundamental na constituição da cidadania, visto ser esta a expressão dos interesses tanto pessoais quanto coletivos dos diferentes sujeitos que atuam criticamente sobre a realidade. Nesse sentido, a educação infantil, como primeira etapa da educação básica, precisa criar um ambiente educativo marcado pelo exercício da cidadania, cuja participação ativa de meninos e meninas, também nos processos de decisão, seja uma constante no cotidiano das instituições. Com isso, educadores e educadoras são desafiados a descentrarem-se da hegemonia adultocêntrica, para que, desde uma perspectiva dialógica, e porque não infantil, possam estimular as crianças no desvelamento e reinvenção do mundo.

Pensar uma educação infantil cidadã, que seja construída com as crianças e não para as crianças, exigirá recriar o ambiente educacional, retirando dele as mordaças e freios que silenciam as vozes das crianças, o seu brincar, suas produções culturais e tudo de criativo, inovador e transgressor que pode destes advir, com vistas à construção de uma sociedade com mais boniteza e justiça social. 


\section{Notas}

1 Nas citações das obras de Paulo Freire, após a data da edição utilizada neste trabalho, a opção foi por colocar entre colchetes [ ] a data da $1^{\mathrm{a}}$ edição, a fim de considerar o período em que suas ideias foram desenvolvidas. Quando estas coincidiram, esse recurso não foi utilizado.

2 Os períodos são: 1) Antes do exílio, em outubro de 1964; 2) O Exílio, de outubro de 1964 a 16 de junho de 1980; 3) Depois do Exílio, de junho de 1980 até a sua saída da Secretaria de Educação do Município de São Paulo, em maio de 1991; 4) Depois da Prefeitura de São Paulo, em maio de 1991, até sua morte em 02 de maio de 1997 e 5) Obras publicadas, postumamente, por Ana Maria Araújo Freire. Para o levantamento bibliográfico da obra de Paulo Freire, os seguintes trabalhos foram utilizados como referências: Paulo Freire: uma biobibliografia (GADOTTI, 1996), A pedagogia da libertação em Paulo Freire (FREIRE, 2001) e Paulo Freire: uma história de vida (FREIRE, 2006).

\section{Referências}

AGAMBEN, Giorgio. Infância e história: destruição da experiência e origem da história. Belo Horizonte: UFMG, 2005.

ARROYO, M. G. O direito à educação e a nova segregação social e racial - tempos insatisfatórios? Educação em Revista, Belo Horizonte, v. 31, n. 03, p. 15- 47, jul./set. 2015.

BARBOSA, I. G.; ALVES, N. N. de L.; MARTINS, T. A. T. Infância e cidadania: ambiguidades e contradições na educação infantil. In: GT-07 EDUCAÇÃO DE CRIANÇAS DE 0 A 6 ANOS. Anais [...]. 2008. Disponível em: http://www.anped.org.br/sites/default/files/gt07-5024-int.pdf. Acesso em: 03 out. 2019.

BRASIL. [Constituição (1988)]. Constituição da República Federativa do Brasil de 1988. Brasília, DF: Presidência da República, 1988.

BRASIL. Lei no 8.069, de 13 de julho de 1990. Dispõe sobre o Estatuto da Criança e do Adolescente e dá outras providências. Brasília, DF, 1990.

BRASIL. Lei no 9.394, de 20 de dezembro de 1996. Estabelece as Diretrizes e Bases da Educação Nacional. Brasília: Ministério da Educação, 1996.

BRASIL. Ministério da Educação. Secretaria de Educação Básica. Diretrizes Curriculares Nacionais para a Educação Infantil. Brasília, DF: MEC; SEB, 2010.

FARIA, A. L. G. de; GOBBI, M. A.; SILVA, M. R. P. da. As infâncias em suas múltiplas imagens: um olhar desde uma perspectiva pós-colonial. In: ARAÚJO, V. C. de. (org.). Infâncias e educação infantil e foco. Curitiba: CRV, 2017. p. 15-30.

FREIRE, A. M. A. (org.). A pedagogia da libertação em Paulo Freire. São Paulo: Unesp, 2001.

FREIRE, A. M. A. (org.). Paulo Freire: uma história de vida. São Paulo: Villa das Letras, 2006.

FREIRE, Paulo. Professora sim, tia não: cartas a quem ousa ensinar. São Paulo: Olho d'Água, 1993.

FREIRE, Paulo. A construção de uma nova cultura política. Fórum de participação popular nas administrações municipais: Poder local, participação popular e construção da cidadania. Belo Horizonte, jun./1994; São Paulo: Instituto Pólis, 1995. Cad.n.1. 
FREIRE, Paulo. Pedagogia da autonomia: saberes necessários à prática educativa. 5. ed. São Paulo: Paz e Terra, 1997 [1996]. (Coleção Leitura).

FREIRE, Paulo. Pedagogia dos sonhos possíveis. São Paulo: Unesp, 2001.

FREIRE, Paulo. Educação e atualidade brasileira. São Paulo: Cortez/IPF, 2001 [1959].

FREIRE, Paulo. Política e educação. 6. ed. São Paulo: Cortez, 2001 [1993]. (Coleção Questões da Nossa Época; v. 23).

FREIRE, Paulo. Pedagogia do oprimido. 35. ed. Rio de Janeiro: Paz e Terra, 2003 [1970].

FREIRE, Paulo. Cartas a Cristina: reflexões sobre minha vida e minha práxis. 2. ed. rev. São Paulo: Paz e Terra, 2003 [1994].

FREIRE, Paulo; GUIMARÃES, Sérgio. Sobre a educação: diálogos. Rio de Janeiro: Paz e Terra, 1982. (v. 1).

FREIRE, Paulo; GUIMARÃES, Sérgio. Sobre educação: diálogos. Rio de Janeiro: Paz e Terra, 1984. (v. 2).

FREIRE, Paulo; FAUNDEZ, Antônio. Por uma pedagogia da pergunta. 8. ed. Rio de Janeiro; São Paulo: Paz e Terra, 2017 [1985].

GADOTTI, Moacir (org.). Paulo Freire: uma biobibliografia. São Paulo: Cortez: Instituto Paulo Freire; Brasília, DF: UNESCO, 1996.

GALEANO, Eduardo. De pernas pro ar: a escola do mundo ao avesso. Porto Alegre: L\&PM, 1999.

KOHAN, W. O. Paulo Freire: outras infâncias para a infância. Educação em Revista, n. 34, p. 1-20, 2018. Disponível em: https:/www.scielo.br/scielo.php?script=sci_abstract\&pid=S0102-46982018000100173\&lng=pt\&nrm=iso. Acesso em: 20 ago. 2020.

KOHAN, W. O. Paulo Freire e a (sua) infância educadora. In: SILVA, M. R. P. da; MAFRA, J. F. (org.). Paulo Freire e a educação das crianças. São Paulo: BT Acadêmica, 2020. p. 83-100.

LARROSA, Jorge. Pedagogia profana: danças, piruetas e mascaradas. 4. ed. Belo Horizonte: Autêntica, 2003.

ONU. Declaração Universal dos Direitos da Criança. 1959. Disponível em: http://www.direitoshumanos.usp.br/index.php/Crian\%C3\%A7a/declaracao-dos-direitos-da-crianca.html. Acesso em: 03 out. 2019.

ONU. Convenção sobre os Direitos da Criança. 1989. Disponível em: https://www.unicef.org/brazil/convencao-sobre-os-direitos-da-crianca. Acesso em: 03 out. 2019.

QVORTRUP, Jens. Infância e política. Cadernos de Pesquisa, São Paulo, v. 40, n. 141, set./dez. 2010. Disponível em: http://publicacoes.fcc.org.br/ojs/index.php/cp/article/view/147/146. Acesso em: 03 nov. 2019.

SANTOS NETO, E. dos; SILVA, M. R. P. da. Infância e inacabamento: um encontro entre Paulo Freire e Giorgio Agamben. 2006, p. 1-13. Disponível em: http://www.egov.ufsc.br/portal/conteudo/inf\%C3\%A2ncia-e-inacabamento-um-encontro-entre-paulo-freire-e-giorgio-agamben. Acesso em: 13 jun. 2020. 
SARMENTO, M. J.; FERNANDES, N.; TOMÁS, C. Políticas públicas e participação infantil. Educação, Sociedade \& Culturas, n. 25, p. 183-206, 2007.

SARMENTO, M. J.; SOARES, N.; TOMÁS, C. Participação social e cidadania activa das crianças. 2004. Disponível em: http://www.acervo.paulofreire.org:8080/jspui/bitstream/7891/3842/1/ FPF_PTPF_01_0563.pdf. Acesso em: 03 out. 2019.

SARMENTO, M. J.; PINTO, M. As crianças e a infância: definindo conceitos delimitando o campo. In: PINTO, M.; SARMENTO, M. J. (coord.). As crianças: contextos e identidades. Braga, Portugal: Centro de Estudos da Criança, 1997. p. 9-30.

SILVA, M. R. P. da. Por uma educação infantil emancipatória: a vez e a voz das crianças e de suas professoras. Cadernos de Educação, Dossiê, v. 58, p. 83-100, 2017. Disponível em: https:// periodicos.ufpel.edu.br/ojs2/index.php/caduc/article/view/12370. Acesso em: 10 maio 2020.

SILVA, M. R. P. da; FASANO, E. Crianças e infâncias em Paulo Freire. In: SILVA, M. R. P.; MAFRA, J. F. (org.). Paulo Freire e a educação das crianças. São Paulo, Brasil: BT Acadêmica, 2020. p. 57-82.

SOARES, N. F. Infância e direitos - participação das crianças nos contextos de vida - representações, práticas e poderes. Tese (Doutorado em Estudos da Criança) - Universidade do Minho, Braga, 2005.

TONUCCI, Francesco. Quando as crianças dizem: agora chega! Porto Alegre: Artmed, 2005.

TONUCCI, Francesco. A solidão da criança. Campinas: Autores Associados, 2008.

VANNUCCHI, Aldo; SANTOS, Wlademir dos; FREIRE, Paulo. Paulo Freire ao vivo. São Paulo: Edições Loyola, 1983. 